\title{
COMMUNITY PERCEPTION ON SHARIA HOSPITAL IN INDONESIA
}

\author{
Anyta Ekaningsih, Adang Bachtiar
}

Faculty of Public Health, Universitas Indonesia

\begin{abstract}
Background: Global competition of hospital services has been increasing currently. Sharia hospital becomes something new in the community. This raises the questions regarding the perception of Sharia hospital among the community. This study aimed to determine community perception on Sharia hospital in Indonesia.

Subjects and Method: This was a cross sectional study conducted at Sharia hospital. A total of 74 study subjects was selected for this study. The dependent variable was community perception. The independent variables were information access, trust, and service standard. The data were collected using online survey in February 2019. Data were described accordingly.

Results: Community perception of the Sharia Hospital was positive (52\%). Community perception of the Sharia hospital was positively associated with information, trust, and service standard.

Conclusion: About $52 \%$ of community perception of the Sharia Hospital is positive. Information, trust, and service standard, are positively associated with community perception.
\end{abstract}

Keywords: perception, community, Sharia hospital

\section{Correspondence:}

Anyta Ekaningsih. Faculty of Public Health, Universitas Indonesia, Depok, West Java, Indonesia. Email: anyta.eka.n@gmail.com. Mobile: 085710894090. 